\title{
Les résidences aristocratiques du viennois, Canton de Saint-Jean-de-Bournay
}

$n^{\circ} 2211319$

\section{Guillaume Tisserand}

\section{(2) OpenEdition \\ Journals}

Édition électronique

URL : http://journals.openedition.org/adlfi/15156

ISSN : 2114-0502

Éditeur

Ministère de la culture

\section{Référence électronique}

Guillaume Tisserand, «Les résidences aristocratiques du viennois, Canton de Saint-Jean-de-Bournay

», ADLFI. Archéologie de la France - Informations [En ligne], Rhône-Alpes, mis en ligne le 30 juillet 2015, consulté le 22 avril 2019. URL : http://journals.openedition.org/adlfi/15156

Ce document a été généré automatiquement le 22 avril 2019

(c) Ministère de la Culture et de la Communication, CNRS 


\section{Les résidences aristocratiques du viennois, Canton de Saint-Jean-de- Bournay}

$n^{\circ} 2211319$

\section{Guillaume Tisserand}

Code INSEE de la commune : 38035, 38094, 38231, 38232, 38346, 38351, 38399, 38555

Lien Atlas (MCC) :

http://atlas.patrimoines.culture.fr/atlas/trunk/index.php?

ap_theme=DOM_2.01.02\&ap_bbox=5.109;45.463;5.182;45.530

1 La prospection menée sur le canton de Saint-Jean-de-Bournay visait à recenser les résidences aristocratiques se trouvant sur le territoire des quinze communes qui le composent. Pour mener cette opération à bien, le parti a été pris de réaliser une étude diachronique au cours de laquelle ont été recensés des sites allant du $\mathrm{IX}^{\mathrm{e}}-\mathrm{X}^{\mathrm{e}} \mathrm{s} . \mathrm{au} \mathrm{XVIII}{ }^{\mathrm{e}} \mathrm{s}$.

Cinquante-neuf sites potentiels ont été identifiés. Parmi eux, on dénombre vingt-neuf sites fosssoyés et trente non fossoyés.

3 Les enquêtes de terrain ont mis en évidence la difficulté d'interprétation des sites fossoyés ceux-ci ayant, depuis leur création, subi les aléas du temps. Nous les avons classés selon la certitude de leur présence. Cette classification les répartit en cinq catégories allant de 0 à 4, 0 indiquant l'absence de site et 4 la présence avérée d'un site. 
INDEX

operation Prospection diachronique (PRD)

Index géographique : Rhône-Alpes, Isère (38), Beauvoir-de-Marc, Chatonnay, Meyrieu-lesEtangs, Meyssies, Royas, Saint-Agnin-sur-Bion, Saint-Jean-de-Bournay, Villeneuve-de-Marc Index chronologique : Moyen Âge, Temps Modernes

Keywords : Medieval Period, Modern Period

\section{AUTEURS}

GUILLAUME TISSERAND

Chercheur bénévole 